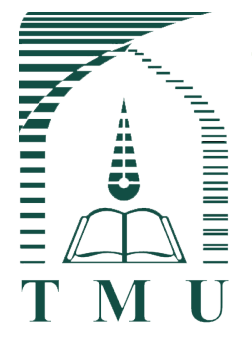

\title{
In Vitro Evaluation of Antimicrobial Properties of Some New 1, 3, 4-0xadiazole Derivatives against Acinetobacter baumannii
}

\section{A R T I C L E I N F O}

\section{Article Type}

Original Article

\section{Authors}

Yasin Sarve Ahrabi, $M S c^{1^{*}}$ Ali Souldozi, $P h D^{2}$

Nakisa Zarrabi Ahrabi, $P h D^{3}$

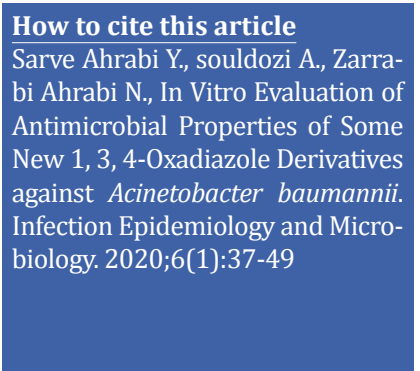

${ }^{1}$ Department of Biology, Central Tehran Branch, Islamic Azad University, Tehran, Iran

2 Department of Chemistry, Urmia Branch, Islamic Azad University, Urmia, Iran

${ }^{3}$ Department of Biology, Central Tehran Branch, Islamic Azad University, Tehran, Iran

\section{* Correspondence}

Address: Department of Biology, Central Tehran Branch, Islamic Azad University, Tehran, Iran yasin.ahrabi2016@gmail.com

\section{Article History}

Received: February 06,2020

Accepted: March 10,2020

Published: March 22,2020

\section{A B S T R A C T}

Aims: The need for new antibacterial drugs is justified because many pathogens are currently resistant to available antibacterial drugs, and this is an alarming threat to the health of future generations. 1, 3, 4-0xadiazole has been shown to pose a wide range of antibacterial activity. Some of the marketed drugs also possess this heterocyclic moiety.

Materials \& Methods: The new derivatives of 1, 3, 4-oxadiazole were synthesized using a single-stage, high-yield method. Then, to measure the antibacterial activity of prepared derivatives agar well diffusion method was employed, and the minimum inhibitory concentration (MIC) and the minimum bactericidal concentration (MBC) were determined at a concentration of $1 \mathrm{mg} / \mathrm{mL}$ with three replications.

Findings: Compounds 4a, 4d, and 4i exhibited a promising antibacterial activity against Acinetobacter baumannii PTCC1855. Among the three compounds mentioned, compound 4i showed the best performance with $\mathrm{IZ}=22 \pm 0.75 \mathrm{~m} . \mathrm{m}, \mathrm{MIC}=500 \mu \mathrm{g} / \mathrm{mL}$ and $\mathrm{MBC}=125 \mu \mathrm{g} / \mathrm{mL}$ at a concentration of $1 \mathrm{mg} / \mathrm{mL}$.

Conclusion: The new 1, 3, 4-0xadiazole derivative (4i) was shown to be a promising compound for pharmaceutical applications, by adding other functional groups to its structure, it is possible to increase the destructive power of the compound.

\section{Keywords: Oxadiazole, Acinetobacter baumannii, Drug resistance}

\section{I T A T I O N L I N K S}

[1] Figueiredo J, Serrano JL, Soares M, Ferreira S, Domingues FC, Almeida P, et. -5Hyd razinylethylidenepyrimidines effective against multidrug-resistant Acinetobacter... [2] Wu X, Wang L, Ye YZ, Yu H. Postoperative multidrug-resistant... [3] Chan PT, Chu KP. A Drug Use Evaluation of Amoxicillin/Clavulanate in... [4] Geisinger E, Huo W, HernandezBird J, Isberg RR. Acinetobacter baumannii: Envelope determinants... [5] Hoang CQ, Nguyen TT, Nguyen HD, Le Tran T, Tran HT, Nguyen ST, et al. Carbapenemase genes and multidrug resistance of Acinetobacter Baumannii: A cross sectional study of patients with pneumonia in Southern... [6] Qin H, Lo NW, Loo JF, Lin X, Yim AK, Tsui SK, et al. Comparative transcriptomics of ... [7] Boll JM, Crofts AA, Peters K, Cattoir V, Vollmer W, Davies BW, et al. A penicillin-binding protein... [8] Domingues S, Rosário N, Cheikh HB, Da Silva GJ. ISAba1 and Tn... [9] Janardhanan J, Chang M, Mobashery S. The oxadiazole ... [10] Khalilullah H, Khan S, Nomani MS, Ahmed B. Synthesis, characterization, and... [11] Gurjar MK, Sonawane SP, Maikap GS, Patil GD, Shinde SB, Shalikrao P, Mehta SS, inventors; Emcure... [12] Souldozi A. Efficient one-pot three-component reaction for the... [13] Wang L, Cao J, Chen Q, He M. One-pot synthesis of -5 2diaryl ,3 1 -4oxadiazoles via... [14] Wong MY, Krotkus S, Copley G, Li W, Murawski C, Hall D, et al. Deep-blue ... [15] Rohand T, Ramli Y, Baruah M, Budka J, Das AM. Synthesis, structure... [16] Karaburun AÇ, Kaya Çavuşoğlu B, Acar Çevik U, Osmaniye D, Sağlık BN, Levent S, et al. Synthesis... [17] Makane VB, Krishna VS, Krishna EV, Shukla M, Mahizhaveni B, Misra S, et al. Novel -4 , 3 ,1oxadiazoles... [18] Basra MA, Batool M, Farhat F, Tajammal A, Khan H. Anti-inflammatory, anti-thrombotic... [19] Rayam P, Polkam N, Kuntala N, Banothu V, Anantaraju HS, Perumal Y, et al. Design and... [20] Shukla C, Srivastava S. Biologically Active Oxadiazole. Journal of ... [21] Shahzad S, Willcox M, Shahzad A. Identification of novel in vitro ... [22] Veeraraghavan B, Vijayakumar S, Pragasam AK, Bakthavachalam YD, Prakash JA. Antimicrobial... [23] Ghasemi B, Najimi M. Antibacterial effect of thiazole derivatives... [24] Geisinger E, Vargas-Cuebas G, Mortman NJ, Syal S, Dai Y, Wainwright EL, et al. The landscape of ... [25] Hsueh, S.C., Lee, Y.J., Huang, Y.T., Liao, C.H., Tsuji, M, .. [26] Lak SS, Souldozi A, Talebi R. Synthesis and evaluation of ... [27] Godhani DR, Mulani VB, Mehta JP. Cyclization and antimicrobial... [28] Seyyed Alipour, B., Fazeli, M., Ahmadi Asb Chin, S., Cheshomi, H., Aldaghi, L. Cytotoxicity effect of... 


\section{Introduction}

Acinetobacter spp. are Gram-negative coccobacilli that require to wet environments for living [1]. The most important species of this genus is $A$. baumannii, causing various diseases such as pneumonia, septicemia, urinary tract infections, skin and wound infections, meningitis, and endocarditis [2]. A. baumannii cloning rate increases in hospitalized people, especially those who have been hospitalized for a long time or have received extensive antibiotic treatment and anti-cancer treatment [3]. One of the main problems is that, A. baumannii could develop resistance to different classes of antibiotics, such as beta-lactams, aminoglycosides, and fluoroquinolones ${ }^{[4]}$. Antibiotic resistance is mostly mediated by genes that are located on mobile genetic elements such as transposons and are easily distributed among bacteria ${ }^{[5]}$. In recent years, $A$. baumannii resistance to gentamicin, streptomycin, spectinomycin, tobramycin, kanamycin, amikacin, neomycin, penicillin, and cephalosporin's has been reported [6-8]. New antibacterial agents which are effective against this bacterium seem to be not available in the near future, increasing the importance of discovering alternative substances. Oxadiazoles were found by in silico docking and scoring of compounds of known three-dimensional structures ${ }^{[9]}$. Oxadiazoles are a category of heterocyclic aromatic compounds belonging to the azole family; with the chemical formula $\mathrm{C}_{2} \mathrm{H}_{2} \mathrm{~N}_{2} \mathrm{O}$. Four isomers of oxadiazole's have been identified so far [10]; among which, 1, 3, 4-Oxadiazole is one of the most important isomers, which isn't commonly employed in chemical science, but many of its derivatives are important. For instance, raltegravir is an HIV drug containing a 1 , 3, 4-oxadiazole ring ${ }^{[11]}$. 1, 3, 4-Oxadiazole derivatives could be synthesized in a variety of ways ${ }^{[12]}$. One pathway is the oxidation of tetrazoles in the presence of aldehydes ${ }^{[13]}$. Similarly, the reaction of tetrazoles with acyl chlorides provides oxadiazoles [14]. Both methods involve the release of $\mathrm{N}_{2}$. In recent years 1, 3, 4-0xadiazole compounds have been reported to exhibit antibacterial [15], antifungal [16], anti-tubercular [17], anti-inflammatory [18] and anticancer [19] activities.

Objectives: As synthesis and evaluation of antimicrobial activity was an important part of this research program [20]; herein, antibacterial activities of 1, 3, 4-Oxadiazole derivatives against A.baumannii PTCC1855 were evaluated. All organic solvents used in this study were new and different from those used in other studies; the one-step method of synthesizing new derivatives was different too.

\section{Materials and Methods}

This Research study was conducted in microbiology laboratory of Islamic Azad University, Tehran branch in 2019. Starting materials, solvents, and culture environments (Mueller-Hinton agar, Mueller-Hinton Broth, Nutrient Broth) were obtained from Merck, Germany and used moving forward without any more filtration. Infrared spectrum was measured by a Shimadzu IR-460 spectrometer. Nuclear magnetic resonance spectrum was obtained by a Bruker DRX-300 AVANCE 


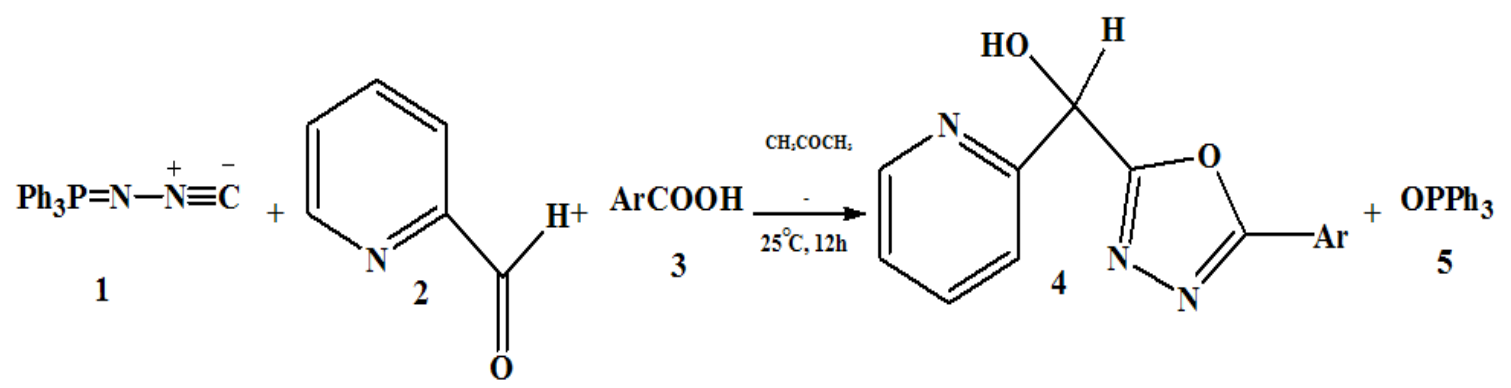

Figure 1) Single-Stage synthesis

spectrometer $\left({ }^{1} \mathrm{H} \mathrm{NMR}\right.$ at $300 \mathrm{~Hz},{ }^{13} \mathrm{C}$ NMR at $75 \mathrm{~Hz}$ ) in $\mathrm{CDCl}_{3}$. Chromatography columns were prepared using silica gel powder (Merck, Germany). The bacterial strain ( $A$. baumannii PTCC1855) was prepared from the Iranian Industrial Microorganisms Collection Center (Lyophilized). Microbiological tests were performed using a Memmert- INC153T2T3 incubator.

Chemistry: 1, 3, 4-oxadiazole compounds were synthesized using a single-stage, high yield method (Figure 1). The chemical structure of all the synthesized compounds was investigated using $\mathrm{H}-\mathrm{NMR}, \mathrm{C}-\mathrm{NMR}$, and IR spectroscopy.

Single-stage: 1. First, N-Iso-cyan-iminotriphenyl-phosphoran (1mmol) + 2-Pyridine-carbaldehyde (1 mmoL) were dissolved in $\mathrm{CH}_{3} \mathrm{COCH}_{3}(7 \mathrm{~mL})$.

2 - In the next step, carboxylic acid ( $1 \mathrm{mmoL}$ ) in $\mathrm{CH}_{3} \mathrm{COCH}_{3}(10 \mathrm{~mL})$ was added to the previous solution (Figure 1) ${ }^{[12]}$.

The final solution was stirred for $12 \mathrm{hrs}$. by a magnetic stirrer at room temperature. The solvent was removed by evaporation, and the viscous residue was purified by flash column chromatography (silica gel powder: petroleum ether-ethyl acetate (4:1)). Thin-layer chromatography and nuclear magnetic resonance indicated that there was no side product (Figure 2).
Table1) Functional groups

\begin{tabular}{cc}
\hline $4 a$ & Ph (Phenyl) \\
\hline $4 \mathrm{~b}$ & Br-Ph (BromoPhenyl) \\
\hline $4 \mathrm{c}$ & $\mathrm{Cl}-\mathrm{Ph}$ (ChloroPhenyl) \\
\hline $4 \mathrm{~d}$ & $\mathrm{~N}$ (Naphthalene) \\
\hline $4 \mathrm{e}$ & $3-\mathrm{Fl}-\mathrm{Ph}$ (FluoroPhenyl) \\
\hline $4 \mathrm{f}$ & $4-\mathrm{Fl}-\mathrm{Ph}$ (FluoroPhenyl) \\
\hline $4 \mathrm{~g}$ & $3,4-\mathrm{Fl}-\mathrm{Ph}$ (DiFluoroPhenyl) \\
\hline $4 \mathrm{~h}$ & $4-\mathrm{M}-\mathrm{Ph}$ (MethoxyPhenyl) \\
\hline $4 \mathrm{i}$ & $3-\mathrm{M}-\mathrm{Ph}$ (MethoxyPhenyl) \\
\hline
\end{tabular}

All substances were dissolved in DMSO (Merck, Germany) at a concentration of 1 $\mathrm{mg} / \mathrm{mL}$, additionally; two antibiotics of, ciprofloxacin (Sigma, cat. no.17850) and ceftazidime (Sigma, cat. no.1847) were used as positive controls.

Antibacterial Activity: Agar well diffusion, MIC, and MBC methods were used to investigate the antibacterial properties of the new synthesized compounds.

Preparation of bacterial suspension: The lipophilic ampoule containing A. baumannii strains was first opened under sterile conditions and transferred to the nutrient broth culture medium and incubated for 24 hours at $37^{\circ} \mathrm{C}$. Then, to ensure that the bacteria were pure in the nutrient broth medium, a linear culture was performed on 
the selective-differential culture medium and incubated for 48 hours at $37^{\circ} \mathrm{C}$. Using a sampler, $1 \mathrm{~mL}$ of 24-hour culture of microbial suspension was transferred to a tube containing sterile nutrient broth, and then the turbidity of the microbial suspension was visually compared to, the McFarland standard set with a spectrophotometer at $625 \mathrm{~nm}$ and absorption rate of $1.5 \times 10^{8} \mathrm{CFU} /$ $\mathrm{mL}$. The Mueller-Hinton agar culture medium was used for agar well diffusion test, and the Mueller-Hinton broth culture medium was used to test the dilution in the tubes. All cultivation environments were prepared according to the manufacturer's instructions and sterilized using autoclave.

Preparation of compound concentrations: Dimethyl sulfoxide (99\%) (DMSO) was used to dissolve all compounds. Initially, a concentration of $1 \mathrm{mg} / \mathrm{mL}$ was prepared from the powders of synthesized compounds and control samples (1:9 ratios). Afterwards, they were kept at $-18^{\circ} \mathrm{C}$ in sterile test tubes until the tests were performed.

Agar well diffusion method: To perform this experiment, wells of $5 \mathrm{~mm}$ in diameter were created by a sterile pipette in MHA culture media containing cultured bacterial suspension. The wells were then filled with synthesized compounds (4a-4i) and positive control samples and put inside the incubator for 24 hours at $37^{\circ} \mathrm{C}$. It is worth noting that all the steps were done near the flame and in a sterile environment [21].

This experiment was repeated three times, and their mean was reported in results.

Broth dilution method: Using the broth dilution method, the minimum inhibitory concentration (MIC) and the minimum bactericidal concentration (MBC) were determined. To determine the MIC, a series of 9 tubes were used to test the different dilutions of each compound. It is noteworthy that the control samples (ciprofloxacin, ceftazidime) were diluted in 9 separate tubes. The initial concentration of each compound was $2 \mathrm{mg} /$ $\mathrm{mL}$, which was obtained by inserting $1 \mathrm{~mL}$ of the compound into the first tube containing $1 \mathrm{~mL}$ of culture medium at a concentration of $1 \mathrm{mg} / \mathrm{mL}$. Different dilutions were obtained from the tube number one ( $2 \mathrm{mg} / \mathrm{mL}$ ) to the tube number $9(0.007 \mathrm{mg} / \mathrm{mL})$. To do this, $1 \mathrm{~mL}$ of compound in the first tube with a concentration of $2 \mathrm{mg} / \mathrm{mL}$ was diluted with $1 \mathrm{~mL}$ of MHB culture medium in the second tube. In this way that $1 \mathrm{~mL}$ was removed from the first tube and added to the second tube containing $1 \mathrm{~mL}$. This was done up to the tube number 9 , then $1 \mathrm{~mL}$ was removed from the last tube and ejected, which eventually resulted in half dilution of the previous tube. Then $50 \mu \mathrm{L}$ of microbial suspension containing $1.5 \times 10^{8}$ bacteria was transferred to the tubes. All the test tubes were placed at $37^{\circ} \mathrm{C}$ for 24 hours. After incubation, the tubes were examined for turbidity due to the bacterial growth. All tubes in which no bacterial growth was observed were sampled and cultured to determine MBC of the compounds. For this purpose, the tubes showing no bacterial growth were cultured on the MHA culture medium, After incubation for 24 hours, the cultured plates were controlled for microbial growth. The lowest concentration of compounds in the relevant plates, exhibiting bacterial growth failure, was considered as the MBC of that compound [22].

\section{Findings}

Chemistry: Infrared, Carbon-Nuclear Magnetic Resonance and hydrogen-Nuclear Magnetic Resonance of all compounds were obtained (Figure 2). 


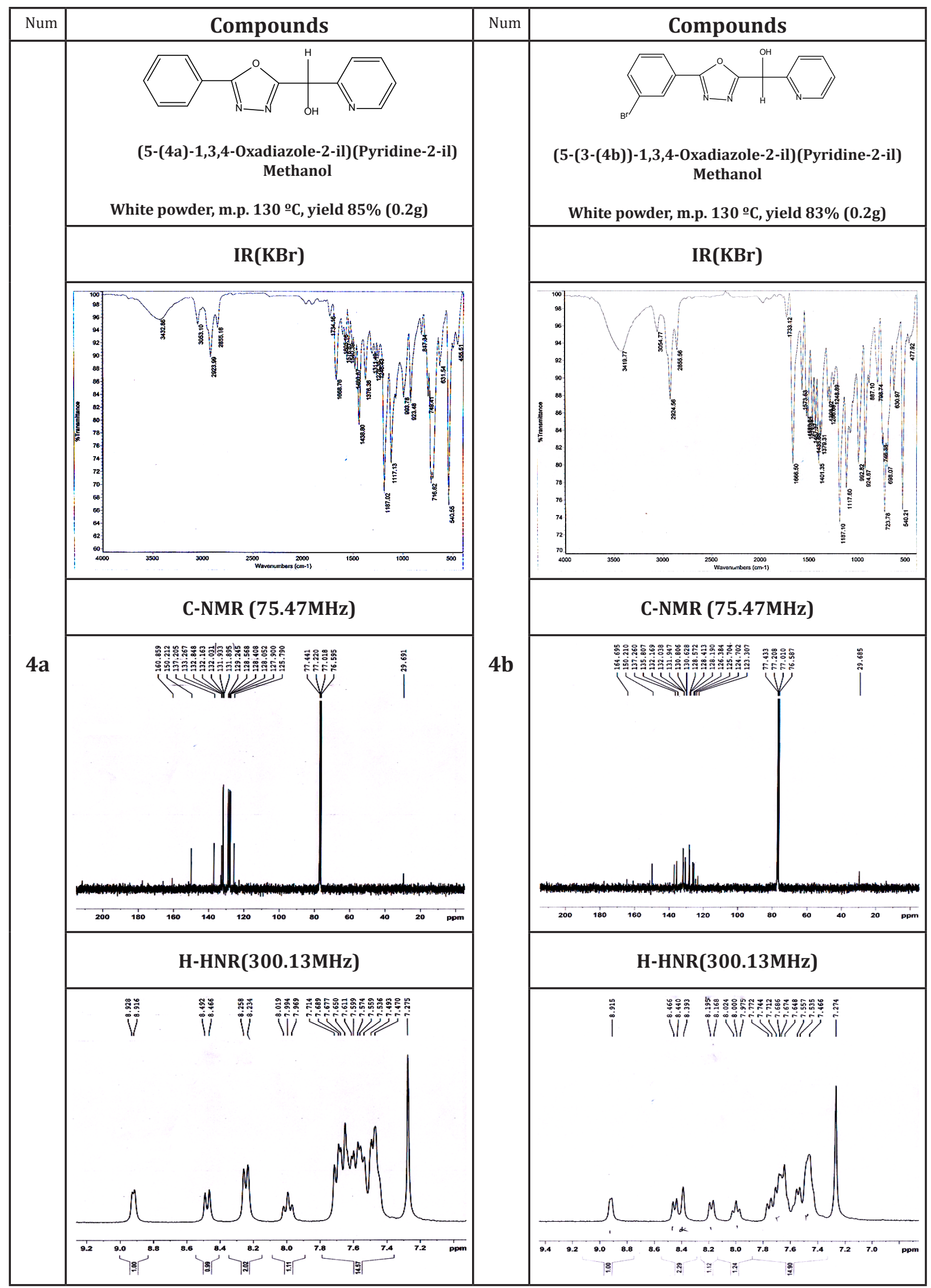

Figure 2) Structural and spectral information of new derivatives of 1, 3, 4-0xadiazole 


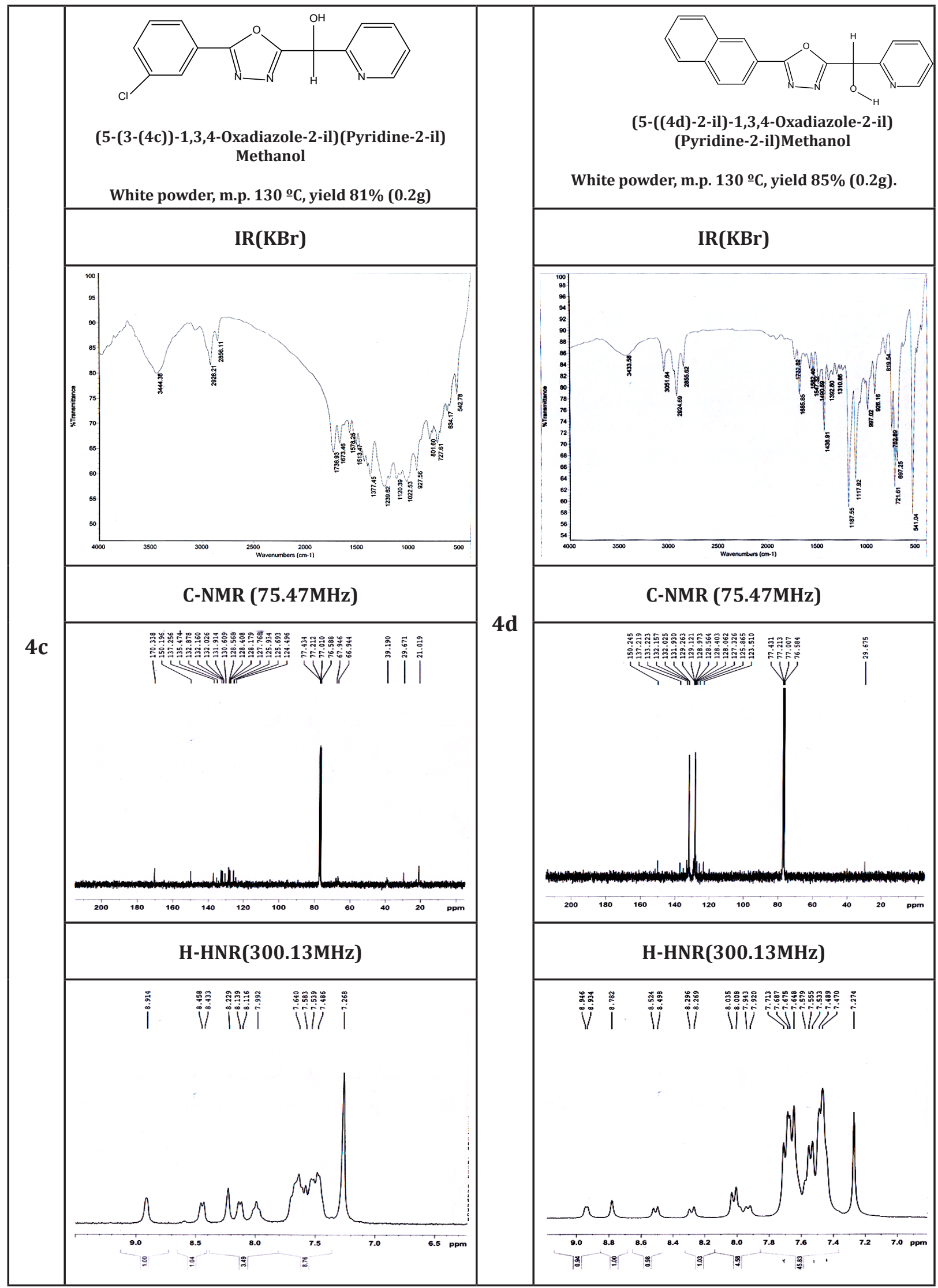

Continue Figure 2 


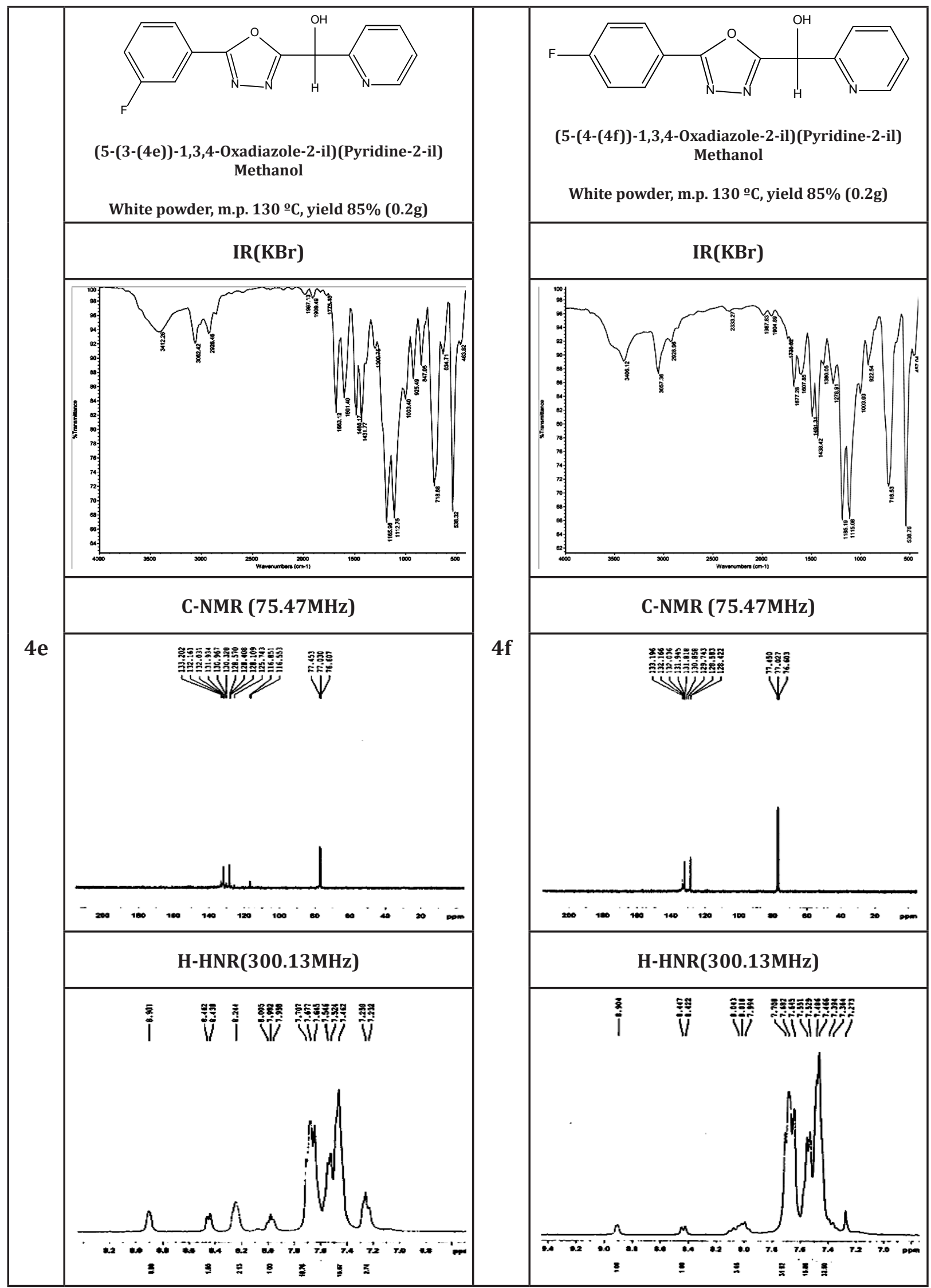

Continue Figure 2 


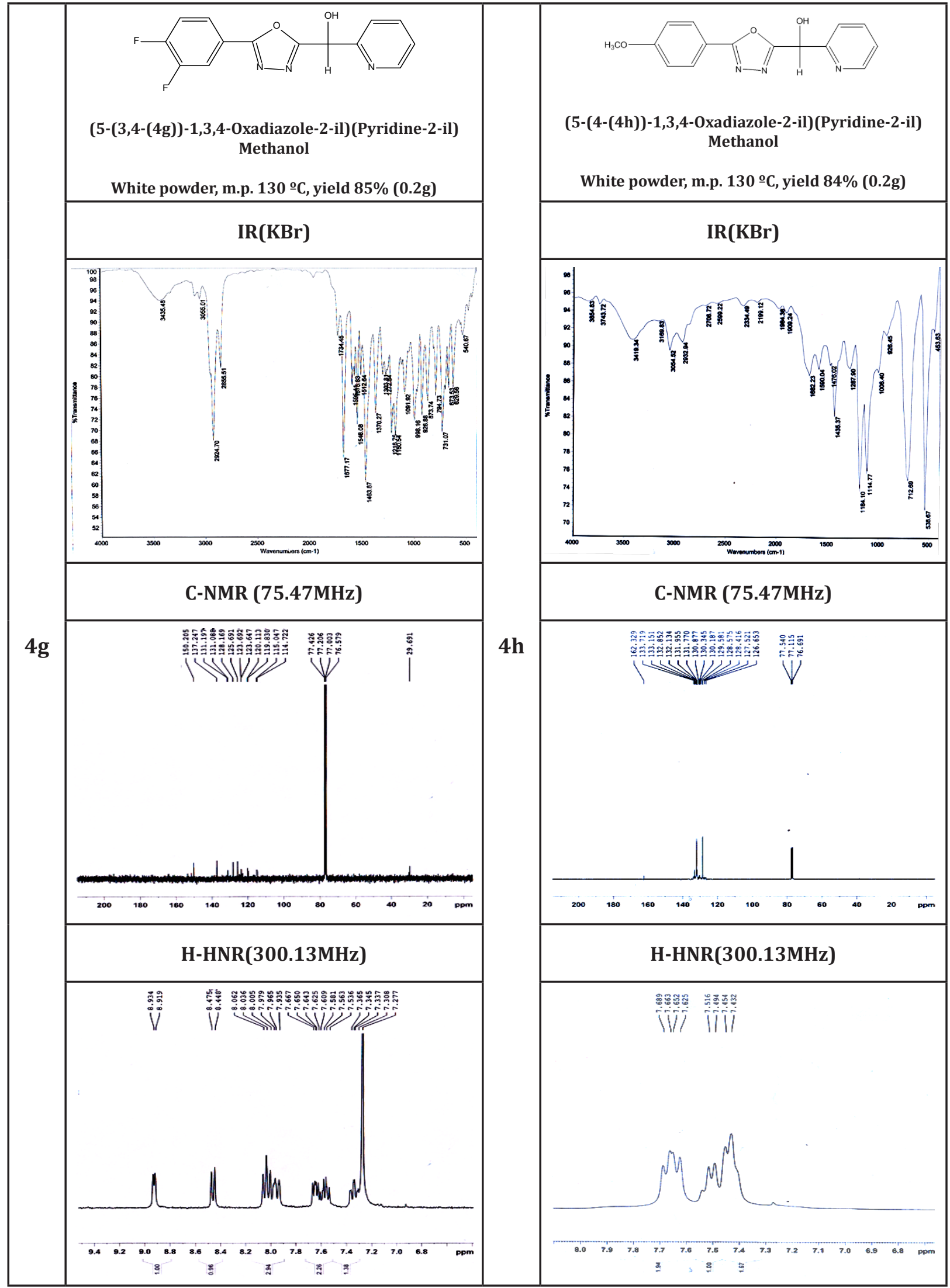

Continue Figure 2 


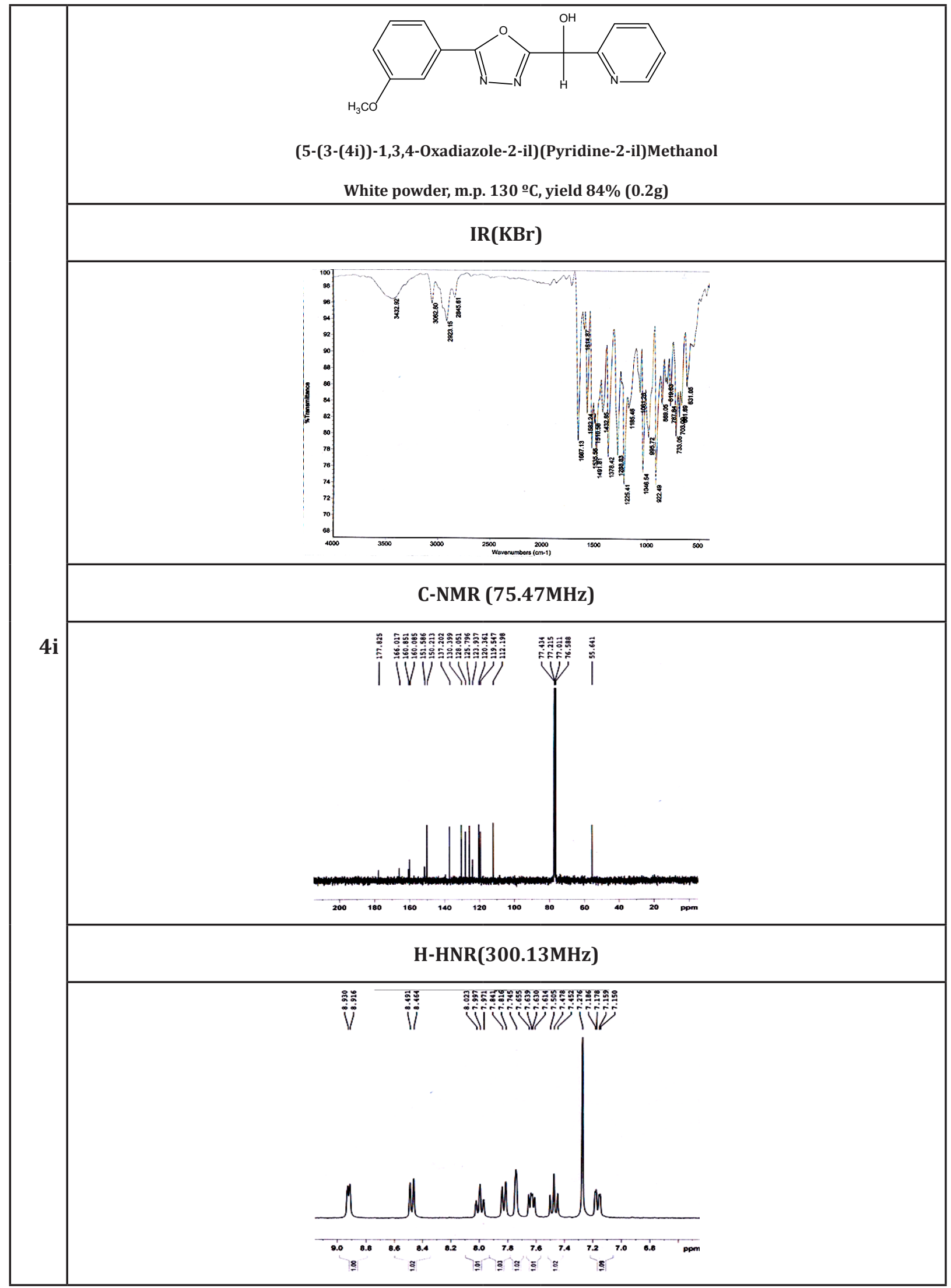

Continue Figure 2 
Diffusion using wells: Antibacterial activity of prepared 1, 3, 4-oxadiazol derivatives (4a-4i) moieties were evaluated in terms of their structure (Figure 2). The inhibition zone results synthesized compounds against tested bacteria are presented in Figure 3. As shown in Figure 3, compound 4i showed high antibacterial activity against $A$. baumannii.
Determination of MIC and MBC: The minimum inhibitory concentrations (MIC) and minimum bactericidal concentrations of tested compounds (4a-4i) are shown in Table 2. The results revealed that compound $4 \mathrm{i}$ was active against $A$. baumannii. The MBC of compounds was the same as or one fold higher than the corresponding MIC results.
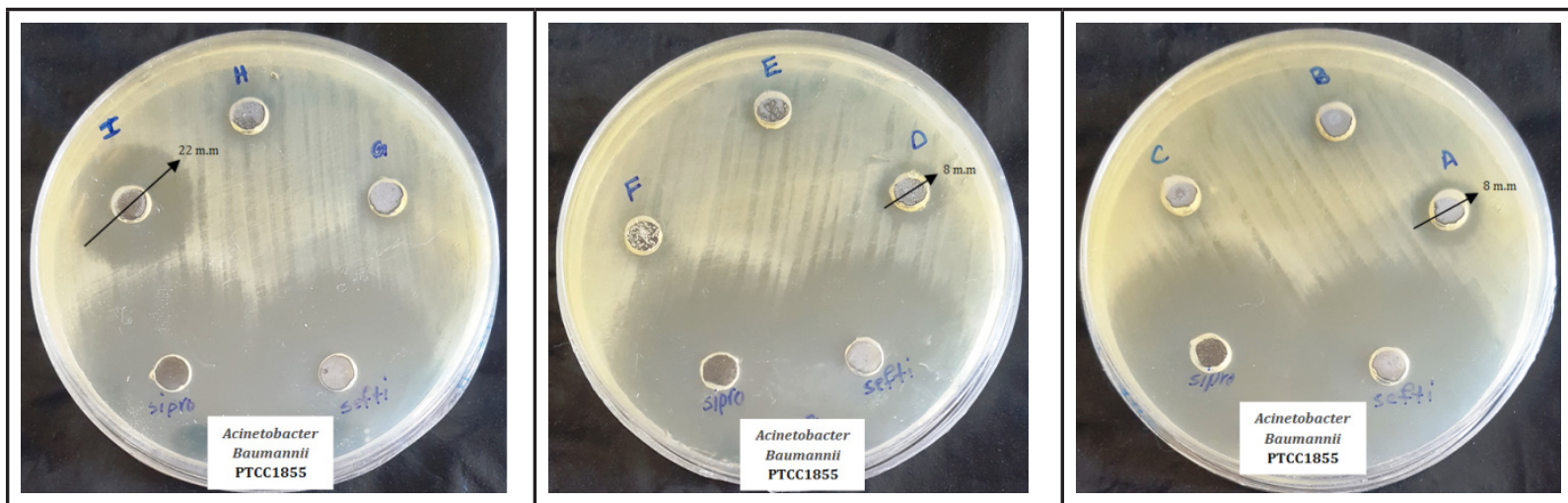

Figure 3) Inhibition zone of compounds against $A$. baumannii at $1 \mathrm{mg} / \mathrm{mL}$ concentration

Table 2) Antibacterial activity of 1, 3, 4-oxadiazol derivatives by Agar well diffusion, MIC, and MBC methods $(1 \mathrm{mg} / \mathrm{mL}) . \pm$ : Averaged three times. NA: No activity

\begin{tabular}{cccc}
\hline & \multicolumn{3}{c}{ A. baumannii PTCC1855 } \\
\cline { 2 - 4 } Compound & IZ & MIC (mg/ml) & MBC (mg/ml) \\
\hline $4 \mathrm{a}$ & $8 \pm 0.5$ & 1 & 0.5 \\
\hline $4 \mathrm{~b}$ & $\mathrm{NA}$ & - & - \\
$4 \mathrm{c}$ & $\mathrm{NA}$ & - & - \\
$4 \mathrm{~d}$ & $8 \pm 0.5$ & 1 & 0.5 \\
$4 \mathrm{e}$ & $\mathrm{NA}$ & - & - \\
$4 \mathrm{f}$ & $\mathrm{NA}$ & - & - \\
$4 \mathrm{~g}$ & $\mathrm{NA}$ & - & - \\
$4 \mathrm{~h}$ & $\mathrm{NA}$ & - & 0.25 \\
$4 \mathrm{i}$ & $22 \pm 0.75$ & 0.5 & 0.125 \\
\hline Ciprofloxacin & $31 \pm 0.5$ & 0.25 & 0.125 \\
\hline Ceftazidime & $29 \pm 0.5$ & 0.25 & \\
\hline
\end{tabular}




\section{Discussion}

Antibiotic resistance is considered as the main crisis in the treatment of infectious diseases caused by bacteria. As a result, the increasing number of antibiotic resistant bacteria isolated from human samples could be a global threat. One way to solve this crisis is to find new antimicrobial compounds to replace current antibiotics. 1, 3, 4-oxadiazol derivatives are novel antibacterial compounds, which are good replacements for a few antibacterial drugs ${ }^{[23]}$. There is no report of A.Baumannii PTCC1855 resistance to $100 \%$ pure ciprofloxacin and ceftazidime powders, but several studies have reported that other strains of A.Baumannii, especially clinical strains, have shown resistance to ciprofloxacin [24] and ceftazidime [25]. In the current study, inhibitory effects of 1 , 3, 4-oxadiazol derivatives were assessed against A.baumannii strains. This bacterium is a multi-drug resistant bacterial pathogen and among the foremost common and dangerous causes of hospital infections; therefore, there is a serious need to develop new antimicrobial compounds to battle these diseases.

According to IZ data, 1, 3, 4-oxadiazole derivatives containing methoxyphenyl (4i), phenyl (4a), and naphthalene (4d) groups showed better activity against bacterial strains. These functional groups, especially $4 \mathrm{i}$, (with methoxyphenyl group), could be used as a new base for antibacterial drugs by creating an inhibitory zone diameter of 22 $\mathrm{mm}$ against the desired bacteria; however, this finding needs to be more investigated by performing further tests, including cell toxicity tests, Also, various tests could also be performed on cancer cell lines to determine the anti-cancer properties of these compounds. In a study by Lak et al. (2017), all of the synthesized compounds used displayed promising antibacterial activity against Gram-positive bacteria. They found that Chlorophenyl group could have a good effect on their samples. They used $\mathrm{CH}_{3} \mathrm{CN}$ as a solvent for their compounds, but in the present study, $\mathrm{CH}_{3} \mathrm{COCH}_{3}$ was used as a solvent to synthesize compounds under study and to enhance their biological effects [26]. Godhani et al. (2019) reported the antimicrobial properties of some new dihydropyrimidine substituted 1, 3, 4-oxadiazole derivatives, which were tested on different bacteria, including $A$. baumannii ATCC 19606. Their synthesized compounds exhibited no effect on A. baumannii strains, but in the present study, compound $4 \mathrm{i}$ exhibited a promising antibacterial activity against $A$. baumannii strains ${ }^{[27]}$. The present study results showed that compound $4 \mathrm{i}$, containing methoxyphenyl group at the C-3 position on thelinker of 1,3,4-oxadiazole, was a potent antibacterial compound with a good MIC. Minimal bactericidal concentration of 4i was almost equal to that of ciprofloxacin and ceftazidime. Methoxyphenyl group is present in the structure of some drugs such as 2- (4- Methoxyphenyl) Acetamide 1(2-Methoxyphenyl) Piperazine, and several other drugs. In another study, Alipour et al. (2015) examined the toxicity effect of new compoundscontainingmethoxyphenylgroup on Hela cells. In their study, methoxyphenyl group exhibited an inhibitory effect on the growth of Hela cancer cells; they studied mechanisms such as induction of apoptosis, and stated that this functional group is likely to cause death ${ }^{[28]}$.

\section{Conclusion}

In this study, 1, 3, 4-oxadiazole derivatives showed a narrow- spectrum antibacterial activity. The obtained results showed that 3-methoxyphenyl could be considered as a useful structure for possible development of new antibacterial drugs. Moreover, the simple workup, high returns, and short response times make the technique very 
helpful in preparing pharmaceutical synthetics.

Acknowledgments: We thanks from Islamic Azad University, Tehran Branch for financial support.

Ethical Permissions: There are no ethical permissions.

Conflicts of Interests: There are no conflicts of interest.

Authors Contribution: YSA and AS: Synthesized new derivatives, YSA and NZA: Examined the antimicrobial properties of derivatives, All authors read, revised, and approved the final manuscript.

Fundings: This research was the continuation of the author's master's thesis (Code: 10330507951009), done in Islamic Azad University, Central Tehran Branch (PhD courses).

\section{References}

1. Figueiredo J, Serrano JL, Soares M, Ferreira S, Domingues FC, Almeida P, et. 5-Hydrazinylethylidenepyrimidines effective against multidrug-resistant Acinetobacter baumannii: Synthesis and in vitro biological evaluation of antibacterial, radical scavenging, and cytotoxic activities. Eur J Pharm Sci. 2019; 137:104964.

2. Wu X, Wang L, Ye YZ, Yu H. Postoperative multidrug-resistant Acinetobacter baumannii meningitis successfully treated with intravenous doxycycline and intraventricular gentamicin: A case report. World J Clin Cases. 2019; $7(24): 4342-8$.

3. Chan PT, Chu KP. A Drug Use Evaluation of Amoxicillin/Clavulanate in Hospital Setting: a Focus on Prescribing Patterns. Hong Kong Pharmaceutical Journal. 2017.

4. Geisinger E, Huo W, Hernandez-Bird J, Isberg RR. Acinetobacter baumannii: Envelope determinants that control drug resistance, virulence, and surface variability. Annu Rev Microbiol. 2019;
73:481-506.

5. Hoang CQ Nguyen TT, Nguyen HD, Le Tran T, Tran HT, Nguyen ST, et al. Carbapenemase genes and multidrug resistance of Acinetobacter Baumannii: A cross sectional study of patients with pneumonia in Southern Vietnam. Antibiotics (Basel). 2019; 8(3):148.

6. Qin H, Lo NW, Loo JF, Lin X, Yim AK, Tsui SK, et al. Comparative transcriptomics of multidrug-resistant Acinetobacter baumannii in response to antibiotic treatments. Sci Rep. 2018; 8(1):3515.

7. Boll JM, Crofts AA, Peters K, Cattoir V, Vollmer W, Davies BW, et al. A penicillinbinding protein inhibits selection of colistin-resistant, lipooligosaccharidedeficient Acinetobacter baumannii. Proc Natl Acad Sci. 2016; 113(41):E6228-37.

8. Domingues S, Rosário N, Cheikh HB, Da Silva GJ. ISAba1 and Tn6168 acquisition by natural transformation leads to thirdgeneration cephalosporins resistance in Acinetobacter baumannii. Infect, Genet Evol. 2018; 63:13-6.

9. Janardhanan J, Chang M, Mobashery S. The oxadiazole antibacterials. Curr Opin Microbiol. 2016; 33:13-7.

10. Khalilullah $H$, Khan S, Nomani MS, Ahmed B. Synthesis, characterization, and antimicrobial activity of benzodioxane ring containing 1, 3, 4-oxadiazole derivatives. Arab J Chem. 2016; 9:S1029-35.

11. Gurjar MK, Sonawane SP, Maikap GS, Patil GD, Shinde SB, Shalikrao P, Mehta SS, inventors; Emcure Pharmaceuticals Ltd, assignee. Synthesis of Raltegravir. United States patent US 9,475,799. 2016.

12. Souldozi A. Efficient one-pot threecomponent reaction for the synthesis of (5-aryl-1, 3, 4-oxadiazol-2-yl)(pyridin2-yl) methanol derivatives. J Chem Res. 2015; 39(3):177-9.

13. Wang L, Cao J, Chen Q He M. Onepot synthesis of 2, 5-diaryl 1, 3, 
4-oxadiazoles via di-tert-butyl peroxide promoted $\mathrm{N}$-acylation of aryl tetrazoles with aldehydes. J Org Chem. 2015; 80(9):4743-8.

14. Wong MY, Krotkus S, Copley G, Li W, Murawski C, Hall D, et al. Deep-blue oxadiazole-containing thermally activated delayed fluorescence emitters for organic light-emitting diodes. ACS Appl Mater. 2018; 10(39):33360-72.

15. Rohand T, Ramli Y, Baruah M, Budka J, Das AM. Synthesis, structure elucidation and antimicrobial properties of new bis1, 3, 4-oxadiazole derivatives. Pharm Chem J. 2019; 53(2):150-4.

16. Karaburun AÇ, Kaya Çavuşoğlu B, Acar Çevik U, Osmaniye D, Sağlık BN, Levent S, et al. Synthesis and antifungal potential of some novel benzimidazole-1, 3, 4-oxadiazole compounds. Molecules. 2019; 24(1):191.

17. Makane VB, Krishna VS, Krishna EV, Shukla M, Mahizhaveni B, Misra S, et al. Novel1,3,4-oxadiazoles as antitubercular agents with limited activity against drugresistant tuberculosis. Future Med Chem. 2019; 11(6):499-510.

18. Basra MA, Batool M, Farhat F, Tajammal A, Khan H. Anti-inflammatory, antithrombotic and molecular docking studies of 1, 3, 4 Oxadiazole derivatives in rats. J Biomed Sci. 2019; 8(2):4.

19. Rayam P, Polkam N, Kuntala N, Banothu V, Anantaraju HS, Perumal Y, et al. Design and synthesis of oxaprozin-1, 3, 4-oxadiazole hybrids as potential anticancer and antibacterial agents. J Heterocycl Chem. 2020; 57(3):1071-82.

20. Shukla C, Srivastava S. Biologically Active Oxadiazole. Journal of Drug Delivery and Therapeutics. 2015 Nov 15;5(6):8-13.

21. Shahzad S, Willcox M, Shahzad A. Identification of novel in vitro antibacterial action of cloprostenol and evaluation of other non-antibiotics against multi-drug resistant
A. baumannii. J Antibiot. 2020; 73(1):72-5.

22. Veeraraghavan B, Vijayakumar S, Pragasam AK, Bakthavachalam YD, Prakash JA. Antimicrobial susceptibility testing methods for Acinetobacter spp. in Acinetobacter baumannii, New York, NY: Humana Press; 2019, pp. 23-37.

23. Ghasemi B, Najimi M. Antibacterial effect of thiazole derivatives on Rhodoccocus equi, Brucella abortus, and Pasteurella multocida. Iran J Vet Med. 2016; 10(1):47-52.

24. Geisinger E, Vargas-Cuebas G, Mortman NJ, Syal S, Dai Y, Wainwright EL, et al. The landscape of phenotypic and transcriptional responses to ciprofloxacin in Acinetobacter baumannii: Acquired resistance alleles modulate drug-induced SOS response and prophage replication. mBio. 2019; 10(3):e01127-19.

25. Hsueh, S.C., Lee, Y.J., Huang, Y.T., Liao, C.H., Tsuji, M, Hsueh, P.R. In vitro activities of cefiderocol, ceftolozane/tazobactam, ceftazidime/avibactam and other comparative drugs against imipenemresistant Pseudomonas aeruginosa and Acinetobacter baumannii, and Stenotrophomonas maltophilia, all associated with bloodstream infections in Taiwan. J Antimicrob Chemother, 2019; 74(2): 380-6.

26. Lak SS, Souldozi A, Talebi R. Synthesis and evaluation of antibacterial activity of 1, 3, 4-oxadiazoles derivatives containing pyridine ring. J Chem Pharm Res. 2017; 9(2):141-6.

27. Godhani DR, Mulani VB, Mehta JP. Cyclization and antimicrobial evolution of 1, 3, 4-oxadiazoles by carbohydrazide. World Sci News. 2019; 124(2):304-11. 28. Seyyed Alipour, B., Fazeli, M., Ahmadi Asb Chin, S., Cheshomi, H., Aldaghi, L. Cytotoxicity effect of synthetic Chalcone derived from 4-Methoxyphenyl on HeLa cell line. J Sabzevar Univ Med Sci, 2015; 22(5): 919-26. 